\title{
Prevention of Collagen Deposition Following Pulmonary Oxygen Toxicity in the Rat by Cis-4-Hydroxy-L-Proline
}

\author{
David J. Riley, Richard A. Berg, Norman H. Edelman, and \\ Darwin J. Prockop, Pulmonary Diseases Division, Departments of Medicine \\ and Biochemistry, College of Medicine and Dentistry of New Jersey-Rutgers \\ Medical School, Piscataway, New Jersey 08854
}

A B S T RACT Exposure of rats to high oxygen tensions causes increased collagen content of lungs and alveolar enlargement in 3-6 wk. We tested whether cis-hydroxyproline, a proline analogue that inhibits collagen synthesis, could prevent the collagen accumulation and alveolar enlargement. Rats were exposed to hyperoxia for $60 \mathrm{~h}$ and then to room air and hyperoxia for alternate 24 -h periods for $11.5 \mathrm{~d}$. Treated oxygenexposed rats received $200 \mathrm{mg} / \mathrm{kg}$ cis-hydroxyproline twice daily over the 14-d exposure period. Control rats breathed room air. Examination of lungs on day 14 showed collagen content of oxygen-exposed lungs to be $48 \%$ greater than control $(P<0.05)$. The collagen content of the treated oxygen-exposed lungs was $-12 \%$ of control (NS). Total lung volume was $16 \%$ greater than control in oxygen-exposed rats $(P<0.05)$ and $8 \%$ greater than control in treated oxygen-exposed rats (NS). Morphometric studies showed alveolar size was greater than control in oxygen-exposed rats $(188 \pm 11$ [SE] vs. $143 \pm 6 \mu \mu \mathrm{l}[P<0.05])$. Oxygenexposed, treated rats had a mean alveolar volume of $150 \pm 7 \mu \mu \mathrm{l}$. Lung pressure-volume curves were significantly shifted to the left of control in the oxygenexposed rats, whereas the curves of the oxygenexposed, treated group were identical to control. These data suggest that cis-hydroxyproline prevented the accumulation of collagen in the lungs in pulmonary oxygen toxicity. In addition, there was apparent protection from airspace dilatation and decreased lung elasticity, suggesting that alveolar enlargement after oxygen toxicity is linked to the deposition in lung tissue of new connective tissue fibers.

\section{INTRODUCTION}

Diffuse alveolar damage can be produced in mammalian species by exposure to high tensions of oxygen

This work was presented at the Annual Meeting of the American Thoracic Society, Las Vegas, Nev., 13-16 May 1979.

Received for publication 12 July 1979 and in revised form 29 October 1979.
(1). The pathologic features in the early stages of oxygen toxicity include endothelial swelling, interstitial edema, and an increase in the predominance of type II alveolar cells $(2,3)$. If the initial injury is not severe and the exposure is discontinued, the pathologic changes may resolve and leave no trace of permanent damage (1). If the exposure is continued beyond this point of reversibility, the pathologic changes may evolve into interstitial fibrosis (1). Pulmonary interstitial fibrosis in rats after exposure to high concentrations of oxygen is manifest on electron microscopic examination of lung tissue $(3,4)$ and as increased collagen content of lungs (5-8).

The structural and mechanical properties of the lungs after recovery from oxygen toxicity are altered in a way not entirely expected from the histologic and biochemical findings of fibrosis. Several investigators have now described airspace enlargement (9-14) and a decreased tissue elastic recoil pressure (15) in rat lung several weeks after recovery from oxygen toxicity. These results suggest decreased structural integrity of the connective tissue framework at a time when lung collagen content is increased above normal.

An explanation of these paradoxical findings is suggested from experimental models of pulmonary emphysema. Weeks to months after the endotracheal instillation of proteolytic enzymes in animals, alveolar enlargement and decreased lung elasticity are found at a time when the content of collagen and elastin in the lung is normal $(16,17)$. It has been postulated that this is due to destruction of connective tissue followed by resynthesis of fibers abnormally arranged in tissue, thereby weakening the structural integrity of the lung (18). If an analogous explanation applies to the rat lung during exposure to toxic concentrations of oxygen, namely, that oxygen toxicity causes both enhanced collagen synthesis and airspace enlargement because of deposition of collagen in an abnormal manner, it might be possible to prevent the structural changes in the lung by inhibiting the synthesis of new connective tissue fibers. 
The goals of the present experiment were $(a)$ to test whether an agent that inhibits collagen biosynthesis could prevent accelerated collagen deposition in rat lung following exposure to toxic levels of oxygen, and $(b)$ to determine whether airspace dilatation could be prevented by inhibiting collagen deposition. The agent used was cis-4-hydroxy-L-proline (cis-hydroxyproline), a proline analogue with relatively specific effects on collagen biosynthesis. Collagen is exceptionally rich in proline and trans-4-hydroxyL-proline (hydroxyproline), and incorporation of proline analogues into collagen polypeptides in sites normally occupied by proline and hydroxyproline prevents these chains from folding into the native triple-helical conformation required for collagen to polymerize into functional fibrils $(19,20)$.

\section{METHODS}

A total of 148 adult, male Sprague-Dawley rats (Camm Research Institute, Wayne, N. J.), 6 wk of age and 180-190 g in body wt, were studied. Complete studies were done on three groups of animals: control, oxygen exposed, and oxygen exposed, treated with proline analogue. Approximately two-thirds of the animals in each group were used for both lung mechanical and biochemical studies and the remaining one-third for morphologic studies. In addition, a second control group of rats were exposed to room air and treated with the proline analogue to determine the effect of the analogue itself on body weight and collagen content of the lungs.

General protocol. The protocol for oxygen exposure was a modification of that described by Välimäki et al. (5). Rats in the oxygen-exposed group were placed in containers $28 \times 28 \times 12 \mathrm{~cm}$ in size. Three rats were placed in each container. Oxygen flowed into the container at a rate of $\sim 1$ liter/min per rat to keep the oxygen concentration between $90-95 \%$ and the carbon dioxide concentration $<0.4 \%$. The animals were first exposed to hyperoxia $(90-$ $95 \%$ oxygen at 1 atm pressure) continuously for $60 \mathrm{~h}$. Thereafter, the animals breathed room air and hyperoxic gas for alternate 24 -h periods for an additional $11.5 \mathrm{~d}$. All measurements were made $14 \mathrm{~d}$ after the initial oxygen exposure. The effluent gas from the chamber was sampled daily and was analyzed for oxygen and carbon dioxide tensions electrometrically (Radiometer Co., Copenhagen, Denmark). The oxygen exposure was interrupted once or twice daily for $10-20$-min periods for watering, feeding, and cleaning. Water and food pellets were given ad lib.

The oxygen-exposed, proline analogue-treated group was exposed to hyperoxia and air under exactly the same conditions. In addition, each rat was injected subcutaneously twice daily with $200 \mathrm{mg} / \mathrm{kg}$ body wt cis-hydroxyproline (Ajinimoto U.S.A., New York) in $0.5 \mathrm{ml}$ physiologic saline solution. Control animals were kept in ordinary cages and breathed room air. Proline analogue-treated control animals breathed room air and were injected with cis-hydroxyproline in the same way as the oxygen-exposed, treated group. Animals from all groups were weighed daily.

Chemical analysis. On day 14 , after completion of the lung mechanical studies (see below), each lung was dissected free of all visible bronchi and blood vessels, weighed, and stored at $-20^{\circ} \mathrm{C}$ for subsequent chemical analysis.
Total hydroxyproline and total protein contents of the right lungs were determined as follows. After thawing, each lung was suspended in $6 \mathrm{~N} \mathrm{HCl}$ and autoclaved at $116^{\circ} \mathrm{C}$ for $16 \mathrm{~h}$. The hydrolysate was clarified, filtered, and evaporated. The residue was dissolved in water, and aliquots were assayed in triplicate for hydroxyproline using the method of Kivirikko et al. (21). Elastin should not alter the determination of collagen by measuring hydroxyproline content because it is composed of $<1 \%$ hydroxyproline in human lung tissue (22). Aliquots were also reacted in triplicate with ninhydrin for determination of total protein content (23). Leucine was used as the standard. Hydroxyproline and protein were expressed per whole lung.

Left lungs were assayed for DNA content. Each lung was homogenized in a glass and Teflon homogenizer (DuPont, E. I., de Nemours \& Co., Inc., Wilmington, Del.) in $0.5 \mathrm{~N}$ perchloric acid and prepared for analysis as described by Merchant et al. (24) except that the first step using $0.5 \mathrm{~N}$ perchloric acid was adjusted to $20 \mathrm{ml} / \mathrm{g}$ wet wt of lung. DNA was assayed in triplicate, using a modification of the Burton method (25) as described by Merchant et al. (24). The observed values for DNA were used to calculate DNA content per lung.

Lung mechanics. On day 14, each rat was anesthetized with $50 \mathrm{mg} / \mathrm{kg}$ body wt pentobarbital i.p. A tracheal cannula was inserted through an incision in the neck, and the lungs were degassed by clamping the cannula $10 \mathrm{~min}$ after the animal had breathed $100 \%$ oxygen. Animals were killed by sectioning the abdominal aortas. The diaphragms were removed, a medial sternotomy performed, and the ribs spread widely apart. The lungs were considered to be air-free if they were a uniform deep red color.

With minor modifications, we used the method of Karlinsky et al. (26) to assess the tissue elastic properties of lungs by determining the static pressure-volume relationships during saline inflation. The thorax containing the degassed lungs, heart, and mediastinal structures were removed en bloc from the rest of the body, weighed, and placed in a large water bath containing physiologic saline solution maintained at $37^{\circ} \mathrm{C}$. The tracheal cannula was connected by a Y-piece adaptor to a saline-filled glass syringe mounted on an infusion-withdrawal pump (model 600-900, Harvard Apparatus Co., Millis, Mass.). The third limb of the Y-piece was connected to a saline-filled pressure transducer (model P23BB, Statham Instruments, Inc., Oxnard, Calif.) positioned at the level of the carina. The pressure signal was continuously displayed on a time base on a strip chart recorder (SP 2006, Statham Instruments). The volume of the saline entering the lungs during infusion and withdrawal was assumed to be equal to the volume change in the syringe.

Lungs were continuously inflated with saline at an infusion rate of $3.88 \mathrm{ml} / \mathrm{min}$. When the pressure reached $25 \mathrm{~cm} \mathrm{H}_{2} \mathrm{O}$, the infusion was stopped; the pressure was noted $10 \mathrm{~s}$ after there was no flow to allow for stress-relaxation. The volume of saline infused to inflate the lungs to $25 \mathrm{~cm} \mathrm{H}_{2} \mathrm{O}$ pressure was referred to as $V_{25}$. The lungs were then deflated in $1 \mathrm{ml}$ steps from $V_{25}$, allowing $10 \mathrm{~s}$ without flow at each step. When $\sim 3 \mathrm{ml}$ remained in the syringe, the saline was withdrawn in $0.5-\mathrm{ml}$ steps until the pressure returned to $0 \mathrm{~cm} \mathrm{H}_{2} \mathrm{O}$.

After completing a single inflation and deflation, the tracheal cannula was clamped, and the lungs-thorax preparation was disconnected from the Y-piece, blotted dry, and reweighed. Weight gain was taken as a measure of the amount of saline retained in the lungs. This volume was added to the volume removed during emptying and compared with the total volume injected to obtain an estimate of leakage. If the estimated leakage was $>5 \%$, the preparation was discarded. Each lung was then prepared for chemical analysis (see above). 
Pressure-volume curves were constructed for each lung by plotting tracheal pressure vs. the volume removed at each interval during deflation of the lungs. Smooth curves were drawn through the data points by hand, and deflation curves for each group were constructed by plotting mean volumes at each $2.5 \mathrm{~cm} \mathrm{H}_{2} \mathrm{O}$ interval of pressure beginning at zero pressure. Chord compliance, or the slope of a line joining two adjacent points on the deflation curve, was computed for each $2.5 \mathrm{~cm} \mathrm{H}_{2} \mathrm{O}$ pressure interval. Chord compliances for each interval in each group were averaged.

Morphometric studies. Approximately 15 animals from each group (except the proline analogue-treated air-breathing control group) were prepared for morphometric study. After degassing, the lungs were excised and inflated with $10 \%$ phosphate-buffered formalin ( $\mathrm{pH} 7.4$, osmolality $300 \mathrm{mosmol}$ ) to $25 \mathrm{~cm} \mathrm{H}_{2} \mathrm{O}$ pressure. The lung volume was measured by water displacement. The lungs were kept inflated at $25 \mathrm{~cm}$ $\mathrm{H}_{2} \mathrm{O}$ pressure, and volume was remeasured $4 \mathrm{~h}$ later to determine the amount of shrinkage that had occurred during fixation. Using a razor blade, one block of tissue, $2-4 \mathrm{~mm}$ thick, was cut by hand from midcoronal areas of the left lung and from the caudal lobe of the right lung. One side of each block was marked with India ink, and the linear dimensions of this side were measured to compute area. Each block of tissue was embedded in paraffin, cut parallel to the marked side into $4-\mu \mathrm{m}$ thick sections, stained with hematoxylineosin, and mounted for light microscopic examination. The linear dimensions of the mounted sections were remeasured, and the change in area from the fixed to the processed state was computed to correct for shrinkage from processing (27).

Morphometric investigation of the lung was performed using light microscopy. Two slides from each block of tissue were randomly selected, and five microscopic fields from each slide were chosen at random and photographed. Photographs were analyzed using a table projector unit that projected the picture onto a screen containing a grid (28). The final magnification was $\times 354$. Differential volumetry was performed by point counting. The volume density of parenchyma $\left(V_{v p}\right)$ and parenchymal airspaces $\left(V_{v p a}\right)$ was determined using the (riteria of Burri et al. (29). Counting was done by a single observer without knowledge of the treatment groups being evaluated. A sufficient number of points were counted to reduce the standard error as a percentage of the mean to $<5 \%$.

The mean linear intercept, $\mathrm{L}_{m}$ (the average distance between alveolar surfaces), was measured by counting the total number of intercepts of alveolar walls with lines of known length (27). The alveolar surface area per lung $\left(S_{A T}\right)$ was computed using the mean cord length method $(27,30)$. We also estimated the size of alveoli by directly measuring the linear dimensions of alveoli and by computing alveolar volume using a method described by Weibel (31). In this method, each alveolus is assumed to be a simplified geometric model shaped like a truncated cone joined to a cone-shaped dome. In each lung, the dimensions of 30 randomly selected alveoli were measured, multiplied by a Lenz coefficient factor of $1.2(31)$, and converted to the dimensions in the fresh state. Alveolar volumes were averaged for each group.

An estimate of the number of alveoli per lung was made by counting the alveoli per unit area and then applying the Weibel-Gomez formula (32) as modified by Weibel (33), the shape coefficient $(\beta)$ equaling $1.55(32)$ and the distribution coefficient $(\mathrm{K})$ equaling 1.05 (33).

Histology. Sections from each lung were stained with Masson's trichrome and van Gieson's stain for examination of connective tissue with light microscopy. Cellularity was evaluated using hematoxylin-eosin stained sections. Two pathologists graded the sections without knowledge of the experimental conditions. The following were graded on a scale of 1 (normal) to 4 (severe): fibrosis, alveolar wall thickening, alveolar destruction, and interstitial cellularity.

Statistical analysis. Data from the groups of animals were analyzed statistically using one-way analysis of variance (34) followed by a Student-Newman-Keuls procedure (34). A P value of $<0.05$ was considered significant.

\section{RESULTS}

Animal survival and change in body weight. 33 of $50(66 \%)$ animals in the oxygen-exposed group and 39 of $69(57 \%)$ in the oxygen-exposed, proline analoguetreated group survived the exposure period. All 22 animals in the control group and all 7 in the treated control group survived. Rats that died manifested progressive respiratory distress; all deaths occurred between the 3rd-6th $d$ of the exposure period. Using gross and light microscopic examination, we found no evidence of pulmonary infection in any rat. During the 2-wk exposure period, animals in the control group gained $24 \%$ in body wt, treated control animals $28 \%$, oxygen-exposed animals $18 \%$, and oxygen-exposed, treated animals $6 \%$. The mean body weight of the oxygen-exposed, treated group on day 14 was significantly less than the other groups $(P<0.05)$.

Biochemical assays. Biochemical assays were performed on 12 animals in each of the control, oxygenexposed, and oxygen-exposed, treated groups, The results are summarized in Fig. 1. The right lungs of the control group contained $\sim 1.53 \mathrm{mg}$ hydroxyproline. Because $\sim 10 \%$ of the amino acids in collagen are represented by hydroxyproline (35), the right lungs of the control group contained $\sim 15.3 \mathrm{mg}$ collagen. The lungs of the oxygen-exposed group contained $\sim 2.25 \mathrm{mg}$ hydroxyproline (22.5 mg collagen), a significant increase compared with control $(P<0.05)$. The lungs of the oxygen-exposed, treated group contained $1.40 \mathrm{mg}$ hydroxyproline ( $14.0 \mathrm{mg}$ collagen). This value was significantly less than the oxygen-exposed group $(P<0.05)$. Thus, oxygen exposure significantly increased total lung collagen. This effect was not observed when oxygen exposure was combined with administration of cishydroxyproline (Fig. 1).

Not shown in Fig. 1 are the biochemical assays of the group of air-breathing animals treated with cis-hydroxyproline. This group had a mean hydroxyproline content of $1.48 \pm 0.06 \mathrm{mg}(\mathrm{SE}) /$ right lung, a value almost identical to the value of $1.53 \pm 0.12 \mathrm{mg} / \mathrm{right}$ lung in the control group.

Total protein content was $71 \%$ greater than control in the oxygen-exposed group $(P<0.05)$, and was $19 \%$ greater than control in the oxygen-exposed, treated group (NS) (Fig. 1). The total protein content was significantly less in the oxygen-exposed, treated group compared with the oxygen-exposed group $(P<0.05)$. Thus, cis-hydroxyproline appeared to decrease total protein as well as hydroxyproline accumulation in rat 

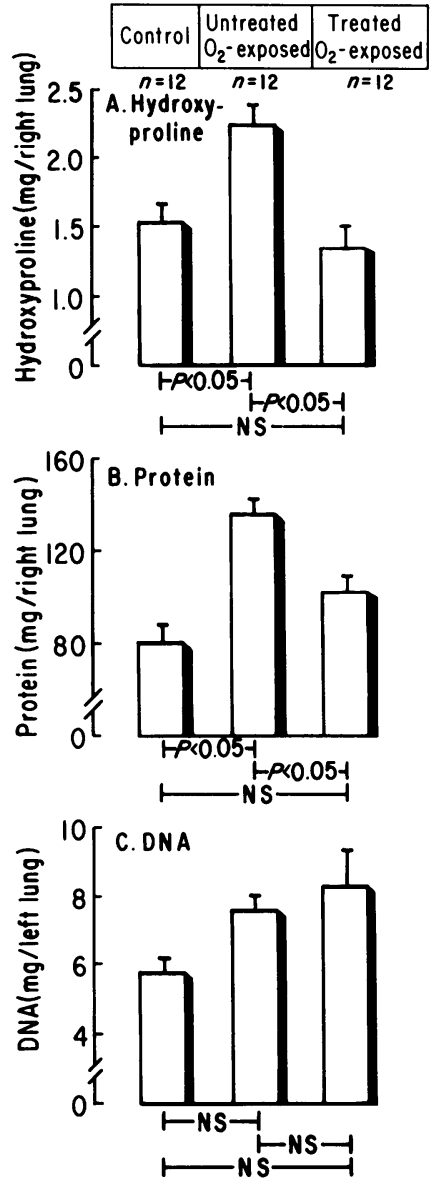

FIGURE 1 Hydroxyproline, protein, and DNA content of lungs. Measurements were done on day 14 of the exposure period on lungs of air-breathing control rats, oxygen-exposed rats, and oxygen-exposed rats treated with cis-hydroxyproline. The bars represent mean data, the bracket 1 SE. Significant differences among the groups at $P<0.05$ level are indicated. (A) Total right lung hydroxyproline. (B) Total right lung protein. (C) Total left lung DNA.

lungs exposed to oxygen. However, administration of the proline analogue caused a greater decrease in hydroxyproline accumulation than in total protein accumulation because the hydroxyproline:total protein ratio was $0.019 \pm 0.002 \mathrm{mg} / \mathrm{mg}$ in the control group, $0.016 \pm 0.002 \mathrm{mg} / \mathrm{mg}$ in the oxygen-exposed group, and $0.012 \pm 0.003 \mathrm{mg} / \mathrm{mg}$ in the oxygen-exposed, treated group. The ratio was significantly less in the group treated with the proline analogue compared with the other two groups $(P<0.05)$.

There were no statistically significant differences in the lung DNA content (Fig. 1), suggesting that the cellularity of the lungs of the three groups of animals was the same at the time of study, $14 \mathrm{~d}$ after the beginning of exposure to oxygen. The hydroxyproline:
DNA ratio was $0.28 \pm 0.06 \mathrm{mg} / \mathrm{mg}$ in the control group, $0.32 \pm 0.07 \mathrm{mg} / \mathrm{mg}$ in the oxygen-exposed group, and $0.17 \pm 0.06 \mathrm{mg} / \mathrm{mg}$ in the oxygen-exposed, treated group. This ratio was significantly less $(P<0.005)$ in the oxygen-exposed, treated group compared with the other two groups, indicating that treatment with cis-hydroxyproline caused a decrease in collagen content per lung cell.

Lung mechanics. Mechanical measurements were completed on lungs from the same 12 animals used in the biochemical assays. Fig. 2 shows the mean deflation limbs of pressure-volume curves for the three groups. When tracheal pressure was plotted against absolute volume (Fig. 2A) and against volume as a percentage of $\mathrm{V}_{25}$ (volume of saline infused to inflate the lungs to $25 \mathrm{~cm} \mathrm{H}_{2} \mathrm{O}$ pressure) (Fig. 2B), the curve of the oxygen-exposed group was shifted upward and to the left of the control group curve. In contrast, the curve of the oxygen-exposed, treated group was virtually identical to the curve of the control group. Statistical analysis of the lung volume at designated pressures showed that the lung volumes at $0,2.5$, and $5.0 \mathrm{~cm} \mathrm{H}_{2} \mathrm{O}$ pressure were significantly greater in the oxygenexposed group than the other two groups $(P<0.05)$. There were no differences in mean chord compliance in any of the designated segments among the three groups.

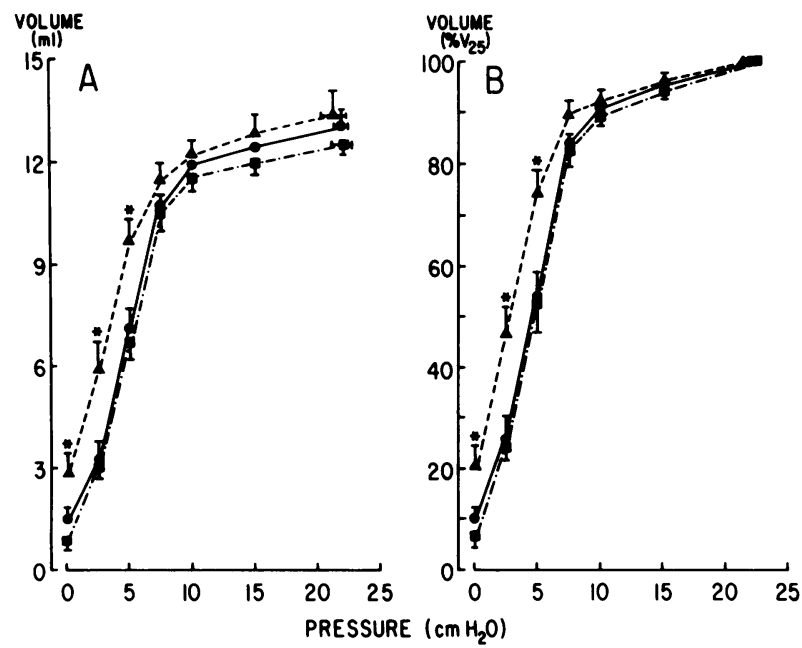

FIGURE 2 Lung deflation pressure-volume curves. Measurements were done on day 14 of the exposure period on lungs of air-breathing control rats $(\boldsymbol{)})$, oxygen-exposed rats $(\boldsymbol{\Delta})$, and oxygen-exposed rats treated with cis-hydroxyproline $(\boldsymbol{\square})$. Data points represent mean data, brackets $\pm 1 \mathrm{SE}$. An asterisk indicates a significant difference in lung volumes at designated pressures between the oxygen-exposed group and both the control and oxygen-exposed, treated groups at the $P<0.05$ level. (A) Absolute lung volume vs. tracheal pressure. (B) Lung volume expressed as percentage of lung volume at $25 \mathrm{~cm} \mathrm{H}_{2} 0$ pressure $\left(\% \mathrm{~V}_{25}\right)$ vs. tracheal pressure. 
Morphometric analysis. Morphometric data and the results of lung volumes determined by water displacement are summarized in Table I. The average lung volume at $25 \mathrm{~cm} \mathrm{H}_{2} 0$ pressure was $16 \%$ greater in the oxygen-exposed group compared with control $(P<0.05)$, and was $8 \%$ greater than control in the oxygen-exposed, treated group (NS). The volume density of parenchyma $\left(V_{\mathrm{vp}}\right)$ and the volume density of parenchymal airspaces $\left(\mathrm{V}_{\mathrm{vpa}}\right)$ were not statistically different among the groups. Mean alveolar volume in the oxygen-exposed group increased $31 \%$ compared with control $(P<0.05)$, but only $5 \%$ in the oxygenexposed, treated group (NS). Treatment with the proline analogue prevented the increase in alveolar size in rats exposed to oxygen because mean alveolar volume was significantly less in the oxygen-exposed, treated group than in the oxygen-exposed group $(P<0.05)$. The same effect of $c i s$-hydroxyproline was apparent when $L_{m}$ (the average distance between alveolar surfaces) was used as an index of size of the airspaces and when total alveolar surface areas $\left(S_{\mathrm{AT}}\right)$ were compared (Table I). Statistically, the number of alveoli per lung was not significantly different among the three groups (Table I). The above data suggest that oxygen exposure under prescribed conditions caused enlargement of alveoli (at $25 \mathrm{~cm} \mathrm{H}_{2} 0$ distending pressure) without decreasing their number, and that treatment with cis-hydroxyproline was effective in preventing the alveolar enlargement.

Histology. There were no significant differences in the light microscopic appearance of the lungs of the oxygen-exposed and oxygen-exposed, treated groups of rats compared with the control group.

TABLE I

Summary of Lung Volume and Morphometric Data

\begin{tabular}{lccc}
\hline & $\begin{array}{c}\text { Control } \\
(n=10)\end{array}$ & $\begin{array}{c}\text { Oxygen-exposed } \\
(n=10)\end{array}$ & $\begin{array}{c}\text { Oxygen-exposed, } \\
\text { treated } \\
(n=10)\end{array}$ \\
\hline $\begin{array}{l}\text { Lung volume, } \\
m l\end{array}$ & $7.47 \pm 0.33$ & $8.68 \pm 0.21^{*}$ & $8.06 \pm 0.34$ \\
$\mathrm{~V}_{\text {vp }}, \%$ & $96.4 \pm 0.3$ & $96.6 \pm 0.6$ & $96.1 \pm 0.6$ \\
$\mathrm{~V}_{\text {vpa }}, \%$ & $68.7 \pm 0.7$ & $71.5 \pm 1.6$ & $70.1 \pm 0.5$ \\
Alveolar size, & & & \\
$\quad(\mu \mu l)$ & $143 \pm 6$ & $188 \pm 11^{*}$ & $150 \pm 7 \ddagger$ \\
$\mathrm{L}_{\mathrm{m}}, \mu m$ & $53.3 \pm 0.8$ & $59.4 \pm 1.0^{*}$ & $56.7 \pm 0.7 * \ddagger$ \\
$\mathrm{S}_{\mathrm{AT}}, \mathrm{cm}^{2}$ & $6,861 \pm 159$ & $7,639 \pm 288^{*}$ & $7,023 \pm 133 \ddagger$ \\
$\mathrm{N}, \times 10^{6}$ & $37.3 \pm 2.7$ & $35.8 \pm 3.0$ & $37.7 \pm 1.6$ \\
\hline
\end{tabular}

Values are $\pm 1 \mathrm{SE} . \mathrm{V}_{\mathrm{vp}}$, volume density of parenchyma; $\mathrm{V}_{\mathrm{vpa}}$, volume density of parenchymal airspaces; $L_{m}$, mean linear intercept; $\mathrm{S}_{\mathrm{AT}}$, total alveolar surface area; $\mathrm{N}$, number of alveoli per lung.

$* P<0.05$ compared with control.

$\$ P<0.05$ compared with the oxygen-exposed group.

\section{DISCUSSION}

Previous studies have shown that several analogues of proline may be incorporated into nascent collagen polypeptides in sites nòmally occupied by proline and hydroxyproline. This substitution prevents folding of the polypeptides into their native triple-helical conformation and, apparently, for this reason decreases the rate at which collagen is deposited in the extracellular matrix (19, 20). Although two proline analogues have been reported to alter hydroxylation of collagen, cis-hydroxyproline has been shown not to have this effect in several systems $(36,37)$.

Parenteral administration of cis-hydroxyproline has been found to limit collagen deposition in laboratory animal models of liver fibrosis, neuroma formation, repair of intestinal anastamoses, tendon adhesions, and granuloma formation (38). However, one group of investigators has found cis-hydroxyproline to be ineffective in inhibiting collagen synthesis in mice or in decreasing the breaking strength of dermal wounds in rodents (39). The basic finding of the present study is that cis-hydroxyproline administration prevents the increased collagen deposition in the lungs of rats after oxygen toxicity. In addition, there was apparent protection from the alveolar enlargement and the lung mechanical changes which are associated with exposure to toxic concentrations of oxygen. Thus, a link between collagen deposition and alveolar enlargement as a result of oxygen toxicity is suggested.

For these studies, oxygen toxicity was chosen as a model of lung injury because it produces diffuse alveolar damage and causes a rapid increase in collagen content of lungs (5). In confirmation of previous studies, $14 \mathrm{~d}$ after the onset of oxygen exposure we found that collagen content was increased by almost $50 \%$ of the control value in oxygen-exposed rat lungs. Cis-hydroxyproline administered to rats under the same exposure conditions prevented the accumulation of collagen. That the analogue was relatively specific for inhibiting collagen deposition in oxygen-exposed rat lung is indicated by the observation that collagen accumulation was inhibited to a greater extent than noncollagen protein accumulation. It should be noted that the colorimetric assay employed in this study detects both hydroxyproline and cis-hydroxyproline; therefore, we may have slightly underestimated the inhibition of collagen deposition (40). There were no gross toxic effects of the cis-hydroxyproline as indicated by the lack of change in body weight and by complete survival of the group of air-breathing rats given the analogue. Therefore, the biochemical results show that under the conditions of this experiment cis-hydroxyproline is an effective agent for inhibiting collagen accumulation in the lungs of rats. 
Although the oxygen-exposed, analogue-treated group of animals had normal lung collagen content and normal lung mechanical properties, survival was no better than in the oxygen-exposed group that did not receive the agent. All deaths occurred between the $3 \mathrm{rd}$ and 6 th d of oxygen exposure. Välimäki et al. (5), using an exposure protocol similar to ours, found no increase in lung collagen on the 5 th $\mathrm{d}$ of exposure. Thus, a lack of improved survival rate in animals treated with cis-hydroxyproline may be explained by the fact that excessive deposition of collagen probably did not occur during the 3rd-6th d after oxygen exposure; other factors (unrelated to excessive collagen deposition) probably contributed to death at this time.

At the time of study, $14 \mathrm{~d}$ after beginning of exposure to oxygen, the light microscopic appearance of tissues was similar in all groups of animals. Serial examination of rat lung tissue during chronic intermittent exposure to oxygen reveals that the cellular reaction is maximal between the 5th and 11th d of exposure; thereafter the inflammatory response rapidly disappears (5). Therefore, we probably found no increase in interstitial cellularity or lung content of DNA on day 14 because the inflammatory response had resolved. We also failed to detect increased collagen in alveolar walls by light microscopy, a result reported by others (5). Conventional collagen stains provide poor contrast for visualizing alveolar collagen (41), and this might explain why increased collagen was not detected by light microscopy. However, it should be noted that electron microscopy has shown increased numbers of collagen bundles in alveolar walls in oxygen-exposed rats $(3,4)$.

The basic findings of the structural and mechanical properties of the lungs after oxygen toxicity were (a) an increased lung volume at $25 \mathrm{~cm} \mathrm{H}_{2} \mathrm{O}$ distending pressure, $(b)$ the morphometric evidence of enlargement of alveoli at $25 \mathrm{~cm} \mathrm{H}_{2} \mathrm{O}$ distending pressure, and (c), in a separate group of animals, a shift to the left of the lower portion of the saline-filled lung pressurevolume curve. Each of these changes was prevented by administration of $c i s$-hydroxyproline during oxygen exposure.

Airspace enlargement has been described on histologic examination of the lungs of rats $(9-14)$, monkeys $(42,43)$, dogs (42), mice (44), and humans (45) after oxygen toxicity. We found no histologic evidence of alveolar wall breakdown; nor was there a decrease in the number of alveoli per lung or in the lung internal surface area on morphometric analysis suggesting an emphysema-like process. The data are qualitatively similar to those of Pratt and Currie (14), and we concur with their conclusion that hyperoxia-induced airspace enlargement in rat lungs was due to overdistension of alveoli rather than "emphysema."

The leftward and upward shift of the pressurevolume curves of the oxygen-exposed, untreated group compared with the control group was consistent with the morphometric studies that showed alveolar enlargement. Acute oxygen exposure causes decireased compliance of fluid-filled lungs $(46,47)$, but Brooksby and Staley (15) reported that the pressure-volume curves of fluid-filled rat lungs studied 3-4 wk after hyperoxia were shifted to the left of control curves. The leftward shift that we found when absolute lung volume was plotted against tracheal pressures in the oxygen-exposed, untreated group (Fig. 2A) cannot be explained by differences in lung size because the shift was present when the data were plotted as percent of maximal volume vs. tracheal pressures (Fig. 2B), a method of analyzing pressure-volume curves that is independent of lung size (48). Starvation has been shown to cause a decrease in the tissue elastic recoil-pressure of the lungs (49), but starvation is an unlikely explanation of our results because the group that gained the least weight (the oxygen-exposed, treated group) had pressure-volume curves identical to the control group.

Because of a leftward and upward shift of the pressure-volume curve without a statistically significant change in slope, the question arises as to whether our finding in oxygen-exposed rat lungs indicates altered lung distensibility. Macklem (50) has emphasized that in human emphysema the characteristic change in the pressure-volume curve is a shift upward and to the left, and that compliance alone is an insensitive way of evaluating the elastic properties of the lung because of the overlap between normal and emphysematous lungs. Furthermore, there is some question whether increased distensibility of the lungs in human emphysema occurs; when the stress-strain relationship of the individual alveolar walls (51) and the compliance of centrilobular emphysematous spaces were measured (52), no increases in distensibility were found. Macklem (50) has suggested that these observations may be explained by a change in resting length rather than distensibility of the connective tissue fibers, and that this change in resting length may occur because the elastin component has been destroyed and the pressure-volume curve reflects more of the collagen component.

The most provocative question raised by the present data is: How may prevention of collagen deposition be linked to preventing overdistension of alveoli? There are several possible explanations. First, Pierce (18) has suggested that in human emphysema there is a rearrangement of connective tissue after the replacement of normal fibers by newly synthesized fibers. By analogy, destruction of connective tissue elements occurs in oxygen-induced lung injury (53) and is followed by resynthesis of fibers. These new fibers are apt to be abnormally arranged in tissue or to lack the tensile strength of normal connective tissue, thereby weakening the structural framework of the lung. 
Studies correlating the morphology of collagen with the tensile strength of tissues have suggested that when the collagen fibers in tissue are less organized and aligned, the tissue is more extensible (54). Also, immature collagen has fewer intermolecular and intramolecular cross-linkages than mature collagen $(55,56)$.

Another possible explanation of the relation of the shift of the pressure-volume curve to increased collagen deposition relates to folding of alveolar walls. There is evidence that decrease in alveolar size during deflation of the normal lung involves folding of alveolar walls (57-60), and it is conceivable that increased collagen in the walls would interfere with this folding. Thus, alveoli would be "held open," causing a shift in the pressure-volume curve. When excessive collagen deposition was prevented, such a shift did not occur. Such a mechanism would be expected to produce the greatest change at low and mid-lung volumes because alveolar folding is thought to occur below $75 \%$ total lung capacity (61). In the present study, the major shift of the pressure-volume curve was at low lung volumes.

A third possibility is that small airway obstruction caused both the shift to the left of the pressure-volume curve and the alveolar enlargement. A recent report suggests that the early pathologic lesions in the human adult respiratory distress syndrome involve alveolar ducts (62). It is possible that oxygen toxicity caused peribronchiolar fibrosis, which in turn caused airflow obstruction; administration of cis-hydroxyproline could have prevented this fibrosis. However, no morphologic evidence of peribronchial fibrosis was found in our oxygen-exposed group.

It is, of course, possible that the observed changes in collagen content per se were unrelated to the changes in the structural and mechanical properties of the lung. Oxygen-induced destruction of other major lung constituents, such as elastin, might account for the alveolar enlargement. Elastin is rich in proline, but prevention of the structural and mechanical changes by the proline analogue would be difficult to explain by a specific effect on elastin; it has been shown that the concentration of cis-hydroxyproline that alters collagen synthesis does not affect the synthesis or secretion of elastin by cells prepared from chick embryo aortas (63).

Finally, it is conceivable that the proline analogue was acting as an antiinflammatory agent to prevent lung injury. The agent could have acted through the complement system because of Clq component of complement contains a collagenlike amino acid sequence (64). At the present time, the biologic effects of proline analogues on the complement system are not known.

\section{ACKNOWLEDGMENTS}

We thank Dr. Bijon K.Ghosh, Dr. Giuseppe Pietra, Dr. Ronald Cody, Mr. Andrew G. Rosenberg, Ms. B. D. Ianni, and Mrs. Bert Rayman.
This investigation was supported by the Freda Wilde Bequest, Delaware-Raritan Lung Association, grants AM 16516, HL 24264, and by a U. S. Public Health Service Pulmonary Academic Award (HL 00443) from the National Heart, Lung, and Blood Institute, National Institutes of Health (Dr. Riley).

\section{REFERENCES}

1. Clark, J. M., and C. J. Lambertsen. 1971. Pulmonary oxygen toxicity: a review. Pharmacol. Rev. 23: 37-133.

2. Kapanci, Y., E. R. Weibel, H. P. Kaplan, and F. R. Robinson. 1969. Pathogenesis and reversibility of the pulmonary lesions of oxygen toxicity in monkeys. II. Ultrastructural and morphometric studies. Lab. Invest. 20: $101-118$.

3. Kistler, G. S., P. R. B. Caldwell, and E. R. Weibel. 1967. Development of fine structural damage to alveolar and capillary lining cells in oxygen-poisoned rat lungs. J. Cell Biol. 32: 605-628.

4. Schaffner, F., P. Felig, and E. Trachtenberg. 1967. Structure of rat lung after protracted oxygen breathing. Arch. Pathol. 83: 99-107.

5. Välimäki, M., K. Juva, J. Rantanen, T. Ekfors, and J. Niinikoski. 1975. Collagen metabolism in rat lungs during chronic intermittent exposure to oxygen. Aviat. Space Environ. Med. 46: 684-690.

6. Välimäki, M., and J. Niinikoski. 1973. Development and reversibility of pulmonary oxygen poisoning in the rat. Aerosp. Med. 44: 533-538.

7. Chvapil, M., and Y. M. Peng. 1975. Oxygen and lung fibrosis. Arch. Environ. Health. 30: 528-532.

8. Hacker, A. D. 1978. Oxygen toxicity and the formation of collagen in the lung. Am. Rev. Respir. Dis. 117: 345. (Abstr.)

9. Brooksby, G. A., R. L. Dennis, and R. W. Staley. 1966. Effects of prolonged exposures of rats to increased oxygen pressures. In Third International Conference on Hyperbaric Medicine. I. W. Brown, Jr., editor. National Academy of Sciences, National Research Publication No. 1404, Washington, D. C. 1: 208-215.

10. Brooksby, G. A., R. L. Dennis, B. Datnow, and D. Clark. 1967. Experimental emphysema. Histologic changes and alterations in pulmonary circulation. Calif. Med. 107: 391-395.

11. Harrison, G. A. 1971. Ultrastructural changes in rat lung during long-term exposure to oxygen. Exp. Med. Surg. 29: $96-107$.

12. Paegle, R. D., D. Spain, and S. Davis. 1974. Pulmonary morphology of chronic phase of oxygen toxicity in adult rats. Chest. 66 (Suppl.): 7S-8S.

13. Tierney, D. F., L. Ayers, and R. S. Kasuyama. 1977. Altered sensitivity to oxygen toxicity. Am. Rev. Respir. Dis. 115 (Suppl.): 59-65.

14. Pratt, P. C., and W. D. Currie. 1977. Pulmonary overdistension in rats following exposure to oxygen inhalation. Am. Rev. Respir. Dis. 115: 366. (Abstr.)

15. Brooksby, G. A., and R. W. Staley. 1966. Static volumepressure relations in lungs of rats exposed to 100 percent oxygen. Physiologist. 9: 144. (Abstr.)

16. Kaplan, P. D., C. Kuhn, and J. A. Pierce. 1973. The induction of emphysema with elastase. I. The evolution of the lesion and the influence of serum. J. Lab. Clin. Med. 82: 349-356.

17. Kuhn, C., III, S-Y. Yu, M. Chraplyvy, H. E. Linder, and R. M. Senior. 1976. The induction of emphysema with elastase. II. Changes in connective tissue. Lab. Invest. 34: $372-380$. 
18. Pierce, J. 1972. Discussion. In Pulmonary Emphysema and Proteolysis. C. Mittman, editor. Academic Press, Inc., New York. 1: 523.

19. Uitto, J., and D. J. Prockop. 1975. Inhibition of collagen accumulation by proline analogues: the mechanism of their action. In Collagen Metabolism in the Liver. $\mathrm{H}$. Popper and K. Becker, editors. Stratton Intercontinental Medical Book Corp., New York. 1: 139-148.

20. Prockop, D. J., K. I. Kivirikko, L. Tuderman, and N. A. Guzman. 1979. The biosynthesis of collagen and its disorders. N. Engl. J. Med. 301: 13-23, 77-85.

21. Kivirikko, K. I., O. Laitinen, and D. J. Prockop. 1967. Modifications of a specific assay for hydroxyproline in urine. Anal. Biochem. 19: 249-255.

22. John, R., and J. Thomas. 1972. Chemical compositions of elastins isolated from aortas and pulmonary tissues of humans of different ages. Biochem. J. 127: 261-269.

23. Moore, S., and W. H. Stein. 1948. Photometric ninhydrin method for use in the chromatography of amino acids. J. Biol. Chem. 176: 367-388.

24. Merchant, D. J., R. H. Kahn, and W. H. Murphy, Jr. 1964. Handbook of Cell and Organ Culture. Burgess Publishing Co., Minneapolis. 2nd edition. 161-167.

25. Burton, K. 1956. A study of the conditions and mechanism of the diphenylamine reaction for the colorimetric estimation of deoxyribonucleic acid. Biochem.J. 62: 315-32.3.

26. Karlinsky, J. B., G. L. Snider, C. Franzblau, P. J. Stone, and F. G. Hoppin, Jr. 1976. In vitro effects of elastase and collagenase on mechanical properties of hamster lungs. Am. Rev. Respir. Dis. 113: 769-777.

27. Dunnill, M. S. 1962. Quantitative methods in the study of pulmonary pathology. Thorax. 17: 320-328.

28. Weibel, E. R. 1973. Stereological techniques for electron microscopic morphometry. In Priniciples and Techniques for Electron Microscopy. III. Biologic Applications. M. A. Hayat, editor. Van Nostrand Reinhold Co., New York. 1: $237-296$.

29. Burri, P. H., J. Dbaly, and E. R. Weibel. 1974. The postnatal growth of the rat lung. I. Morphometry. Anat. Rec. 178: $711-730$

30. Tomkeieff, S. I. 1945. Linear intercepts, areas and volumes. Nature (Lond.). 155: 24.

31. Weibel, E. R. 1963. Morphometry of the Human Lung. Springer-Verlag KG, Berlin. 64-68.

32. Weibel, E. R., and D. M. Gomez. 1962. A principle for counting tissue structures on random sections. J. Appl. Physiol. 17: 343-348.

33. Weibel, E. R. 1963. Morphometry of the Human Lung. Springer-Verlag KG, Berlin. 25-27.

34. Winer, B. J. 1971. Statistical Principles in Experimental Design. McGraw-Hill Book Company, New York. 2nd edition. 210-218.

35. Bradley, K., S. McConnell-Breul, and R. G. Crystal. 1975. Collagen in the human lung. Quantitation of rates of synthesis and partial characterization of composition. J. Clin. Invest. 55: 543-550.

36. Kao, W. W-Y., D. J. Prockop, and R. A. Berg. 1979. Kinetics for the secretion of nonhelical procollagen by freshly isolated tendon cells. J. Biol. Chem. 254: 2234-2243.

37. Uitto, J., and D. J. Prockop. 1974. Incorporation of proline analogues into collagen polypeptides. Effects on the production of extracellular procollagen and on the stability of the triple-helical structure of the molecule. Biochim. Biophys. Acta. 336: 234-251.

38. Uitto, J., and D. J. Prockop. 1975. Molecular defects in collagen and the definition of "collagen disease." In Molecular Pathology. R. A. Good, S. B. Day, and J. J.
Yunis, editors. Charles C. Thomas, Publishers, Springfield, Ill. 1: 670-688.

39. Chvapil, M., J. W. Madden, E. C. Carlson, and E. E. Peacock, Jr. 1974. Effect of cis-hydroxyproline on collagen and other proteins in skin wounds, granuloma tissue, and liver of mice and rats. Exp. Mol. Pathol. 20: $363-373$.

40. Uitto, J., and D. J. Prockop. 1977. Incorporation of proline analogues into procollagen. Assay for replacement of imino acids by cis-4-hydroxy-L-proline and cis-4-fluoroL-proline. Arch. Biochem. Biophys. 181: 293-299.

41. Huang, T. W. 1977. Chemical and histochemical studies of human alveolar collagen fibers. Am. J. Pathol. 86: 81-98.

42. Kaplan, H. P., A. A. Thomas, K. C. Black, and F. R. Robinson. 1968. Evaluation of animals continuously exposed to a 5 psia pure oxygen space cabin atmosphere for eight months. Aerosp. Med. 39: 63-67.

43. Weir, F. W., D. W. Bath, P. Yevich, and F. W. Oberst. 1965. Study of effects of continuous inhalation of high concentrations of oxygen at ambient pressure and temperature. Aerosp. Med. 36: 117-120.

44. Hellstrom, B., and A. Nergardh. 1965. The effect of high oxygen concentration and hypothermia on the lung of the newborn mouse. Acta Paediatr. Scand. 54: 457-466.

45. Kapanci, Y. 1978. Oxygen-induced alveolar lesions in humans and experimental animals. Electron microscopic and morphometric studies. Bull. Eur. Physiopathol. Respir. 14: 128P-129P.

46. Beckman, D. L., and H. S. Weiss. 1969. Hyperoxia compared to surfactant washout on pulmonary compliance in rats. J. Appl. Physiol. 26: 700-709.

47. Gacad, G., and D. Massaro. 1973. Hyperoxia: influence on lung mechanics and protein synthesis. J. Clin. Invest. 52: 559-565.

48. Johnson, J. W. C., S. Permutt, J. H. Sipple, and E. S. Salem. 1964. Effect of intra-alveolar fluid on pulmonary surface tension properties. J. Appl. Physiol. 19: 769-777.

49. Sahebjami, H., C. L. Vassallo, and J. A. Wirman. 1978. Lung mechanics and ultrastructure in prolonged starvation. Am. Rev. Respir. Dis. 117: 77-83.

50. Macklem, P. T. 1972. Discussion. In Pulmonary Emphysema and Proteolysis. C. Mittman, editor. Academic Press, Inc., New York. 1: 522.

51. Martin, C. J., T. S. Sugihara, J. H. Hildebrandt, and A. C. Young. 1970. Length-tension characteristics of alveolar wall in normal man and patients with obstructive syndromes. Am. Rev. Respir. Dis. 101: 452. (Abstr.)

52. Hogg, J. C., S. J. Nepszy, P. T. Macklem, and W. M. Thurlbeck. 1969. Elastic properties of the centrilobular emphysematous space. J. Clin. Invest. 48: 1306-1317.

53. Richmond, V., and B. G. D'Aoust. 1976. Effects of intermittent hyperbaric oxygen on guinea pig lung elastin and collagen. J. Appl. Physiol. 41: 295-301.

54. Stromberg, D. D., and C. A. Wiederhielm. 1969. Viscoelastic description of a collagenous tissue in simple elongation. J. Appl. Physiol. 26: 857-862.

55. Tanzer, M. L. 1973. Cross-linking of collagen. Science (Wash. D.C.). 180: 561-566.

56. Piez, K. A., and A. Miller. 1974. The structure of collagen fibers. J. Supramol. Struct. 2: 121-137.

57. Forrest, J. B. 1976. Lung tissue plasticity: morphometric analysis of anisotropic strain in liquid filled lungs. Respir. Physiol. 27: 223-239.

58. Gil, J., and E. R. Weibel. 1972. Morphological study of pressure-volume hysteresis in rat lungs fixed by vascular perfusion. Respir. Physiol. 15: 190-213.

59. Weibel, E. R., P. Untersee, J. Gil, and M. Zulauf. 1973. 
Morphometric estimation of pulmonary diffusing capacity. VI. Effect of varying positive pressure inflation of air spaces. Respir. Physiol. 18: 285-308.

60. Mazzone, R. W., C. Durand, and J. B. West. 1978. Electron microscopic analysis of factors affecting pulmonary capillary morphology. Fed. Proc. 37: 293. (Abstr.)

61. Forrest, J. B. 1979. Structural aspects of gas exchange. Fed. Proc. 38: 209-214.

62. Pratt, P. C., R. T. Vollmer, J. D. Shelburne, and J. D.
Crapo. 1979. Pulmonary morphology in a multihospital collaborative extracorporeal membrane oxygenation project. I. Light microscopy. Am. J. Pathol. 95: 191-214.

63. Uitto, J., H-P. Hoffmann, and D. J. Prockop. 1976. Synthesis of elastin and procollagen by cells from embryonic aorta. Arch. Biochem. Biophys. 173: 187-200.

64. Reid, K. D. M. 1974. A collagen-like amino acid sequence in a polypeptide chain of human Cla. Biochem. J. 141: 189-203. 